At the annual meeting of the Geological Society of Denmark Dr. R. F. P. Hardman gave a lecture. Dr. Hardman was asked to write an extended review of his lecture. The figures are mainly based on the lecture slides used in Dr. Hardman's presentation. The paper does not represent an extensive literature review but focuses on the current problems of chalk reservoirs in the North Sea region.

\title{
Chalk Reservoirs of the North Sea
}

\author{
R. F. P. HARDMAN
}

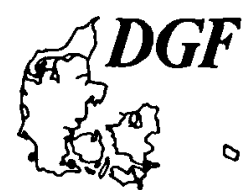

Hardman, R. F. P.: Chalk reservoirs of the North Sea. Bull. geol. Soc. Denmark, vol. 30, pp. 119-137, Copenhagen, September 1st, 1982. https://doi.org/10.37570/bgsd-1981-30-12

\begin{abstract}
In the North Sea, chalk became a reservoir for oil and gas by a combination of fortunate circumstances. Shortly after burial chalk in general has a high porosity, but a low permeability. It is a micropore reservoir. For fluids to enter the pore space, pressure is necessary. North Sea Chalk hydrocarbon fields are all located over thick areas of Kimmeridge and Oxford Clay source rocks on structures which grew during the Tertiary. Structural growth caused fracturing allowing hydrocarbons, which were generated from as early as Oligocene times onwards, to build up in the fracture systems within structural closures in the Chalk. In this way hydrocarbons were able, by their buoyancy or by the pressure generated from the shales below, to enter chalk reservoirs. In areas where Paleocene sands are present, a closed pressure system was not present and no saturation of the Chalk was possible.

Chalk is composed of the debris of coccolithophorids, which being composed of low magnesian calcite is of great chemical stability. Although early diagenetic effects such as compaction by dewatering and loss of aragonite are recognised, burial diagenesis does not start until approximately $1000 \mathrm{~m}$ below surface. In the case of North Sea Chalk reservoirs, diagenesis, which will normally reduce porosity from approximately $50 \%$ at the sea bed to $10 \%$ at between 3000 and $4000 \mathrm{~m}$ burial depth, is arrested by three factors; the pressure generated, as mentioned above, which partially or wholly supports the overburden, thus reducing or preventing pressure solution; oil or gas in the pore space, which, as a chemically inert fluid also largely prevents pressure solution; magnesium ions, present in sea water and in greater concentrations in the pore-waters of up-domed beds overlying Zechstein evaporites, which poison sites of nucleation of calcite retarding diagenesis. As a result all Chalk fields show anomalously high values of porosity. Valhall Field for instance has values of $50 \%$ porosity at a depth of $2500 \mathrm{~m}$.

Chalk reservoir quality is controlled by a variety of factors, but four factors predominate; the purity in terms of calcium carbonate of the sediment; the rate of deposition of the Chalk which in turn determines the degree of early frame-work cement; the tectonic setting of the field area during Chalk deposition; and the size distribution of the coccoliths being deposited.

To these four factors nearly all reservoir quality variation can be related. The best Chalk reservoir in the North Sea is undoubtedly the Tor Formation because of its purity, but the Lower Hod Formation and, in places where allochtonous sheets of Tor Formation have slid in during its deposition, the Ekofisk Formation, can act as very satisfactory North Sea Chalk reservoirs.
\end{abstract}

R. F. P. Hardman, Superior Oil Norge A/S, Kristinelundveien 20 Oslo 2. January 11th 1982.

The chalk is a white limestone of Upper Cretaceous age of wide distribution in North West Europe. It is a pelagic deposit consisting mainly of the disaggregated tests of haplophycean planktonic algae known as coccolithophorids. The material was secreted and deposited as low magnesian calcite which results in a remarkably stable sediment, especially when in contact with marine pore fluids. In addition to coccolithophorid derived material, the Chalk con- tains coarser calcite grains including planktonic and benthonic foraminifera and shell debris of various kinds. It also contains some silt size quartz grains and clay minerals, but in general the Chalk is a remarkably pure form of calcium carbonate. Only at certain well defined stratigraphic horizons do the clay and quartz fractions exceed $15 \%$, and in many zones these two constituents comprise less than $5 \%$ of the rock, the remainder being calcium carbonate. The one exception to 


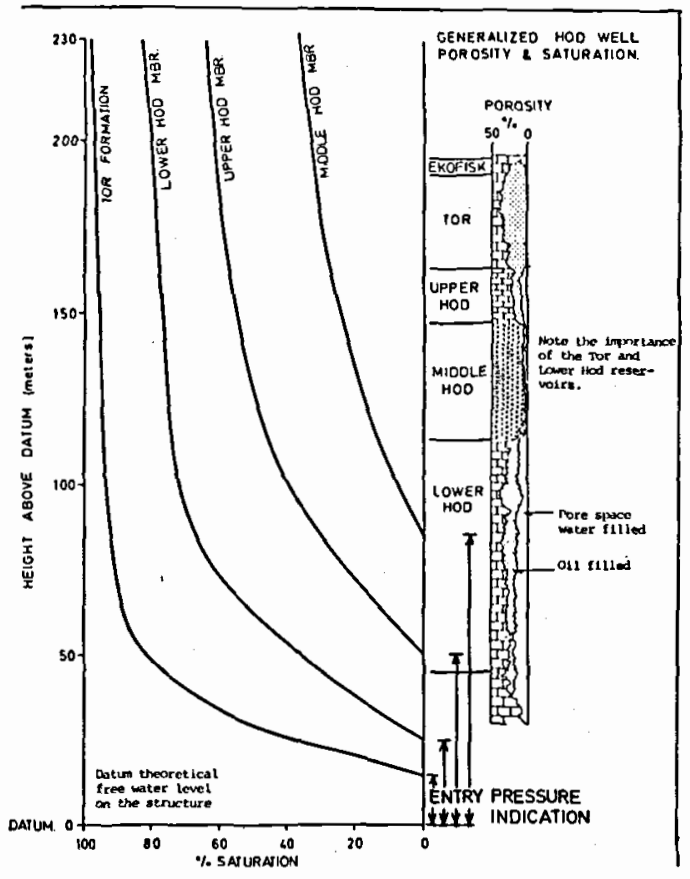

Fig. 1. The Hod fields reservoirs (After Hardman and Kennedy 1980). Entry pressure indications and saturation charateristics average rock.

The curves are for average rock and show that the clay-free Tor Formation is the best reservoir and the clay-rich Middle Hod can almost be considered a seal in the Hod Fields.

this is that early and late stage diagenesis has resulted in cryptocrystalline silica being concentrated in nodules and tabular layers which are known as flints.

The purpose of this paper is to explain the factors which lead to chalk acting as a reservoir for oil and gas in the North Sea in certain areas and not in others, and to understand the factors controlling reservoir quality.

\section{The Chalk as a Reservoir}

Chalk is a micropore reservoir, that is it is composed of particles which are mainly single crystal laths of calcite produced by the disaggregation of coccoliths. These particles are generally in the size range of $0.5-3$ microns with pore throat sizes in the optimum case ranging from 0.1 to $1 \mathrm{mi}$ cron. The size, size range and distribution of pore throats are factors determining the reservoir quality of chalks because unlike sandstones, high porosity chalks with porosities in the range $35-45 \%$ will in favourable cases only exhibit permeabilities in the range $1-3 \mathrm{md}$.

For oil to enter a chalk reservoir a certain entry pressure must be reached which is specific for any given chalk and will be lower for rocks with the more favourable reservoir characteristics and higher for the poorer reservoirs. (Figure 1).

For a chalk reservoir to become hydrocarbon charged therefore a column with a sufficient buoyancy or other pressure must form to overcome the entry pressures, which are specific for each chalk layer, in order for the hydrocarbon to be able to displace the existing pore fluid. Before any hydrocarbon saturation of a chalk can take place, a certain minimum structural closure which will allow excess pressure to be generated must form. The most common way for this to happen is for a hydrocarbon column to develop in the fracture system of a structure which is actively growing during oil migration. Any given rock will only start to become hydrocarbon saturated above a point where its entry pressure has been exceeded by the bouyancy or other pressure of the hydrocarbon column. Consequently, no structure can be found where the chalk is oil charged down to the effective spill point of the closure. It is noted that the Ekofisk Formation (Danian) chalk reservoirs of the Ekofisk Field may be filled to below the limit of apparent structural closure, but the effective seal on these reservoirs appears to be an updip deterioration of reservoir characteristics, believed to be a depositional effect. For any given reservoir fluid, a poor chalk reservoir is one with small pore throats, since it will not start to become hydrocarbon saturated until a high hydrocarbon pressure has been generated, whereas a good chalk reservoir with relatively large pore throats, will become hydrocarbon charged at a much lower pressure. Consequently, over any given structure the poorer reservoirs only exhibit oil saturations in crestal areas whereas saturations in the better reservoirs are recorded considerably down flank on the structure. Valhall Field is a good example of this phenomenon (Figure 2).

In the North Sea the source rocks for the oil found in chalk reservoirs are the organic rich shales of Upper Jurassic age which are often seperated from the chalk by a thick Lower Cretace- 


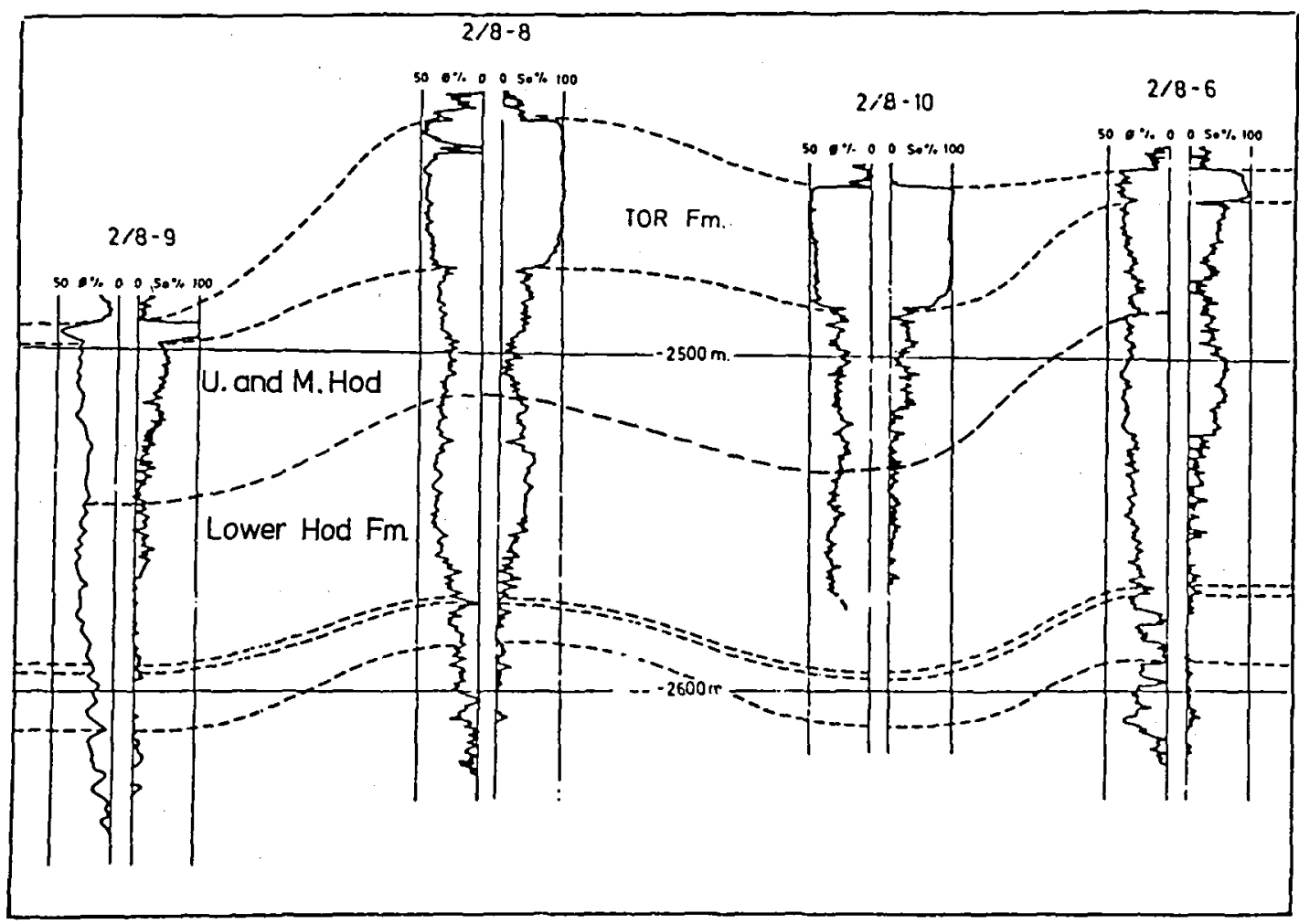

Fig. 2. Petrophysical log section, Valhall Field (after Hardman and Eynon 1977). Saturation and porosity variations for different elevations clearly visible.

ous argillaceous sequence. In order to allow migration of hydrocarbons from the source beds into the overlying chalk through-going fractures are necessary to allow fluid migration from the source beds to the reservoir chalk. Studies show that peak generation of oil by the Kimmeridge Clay of Upper Jurassic age occurred from late Eocene to early Miocene, (Fig. 3), although in many areas it is continuing at the present day. These fractures carried the hydrocarbons into close contact with the chalk, an important consideration in a reservoir of generally low permeability.

One other point that should be mentioned, is that for chalk to become oil charged, the system needs to be sealed and pressure must not escape. Ziegler (1977) has pointed out that chalk fields only exist where Paleocene sandstones are absent. This is quite clearly a result of the ability of the Paleocene sandstones to let the pressure out of the system. (Figure 4).

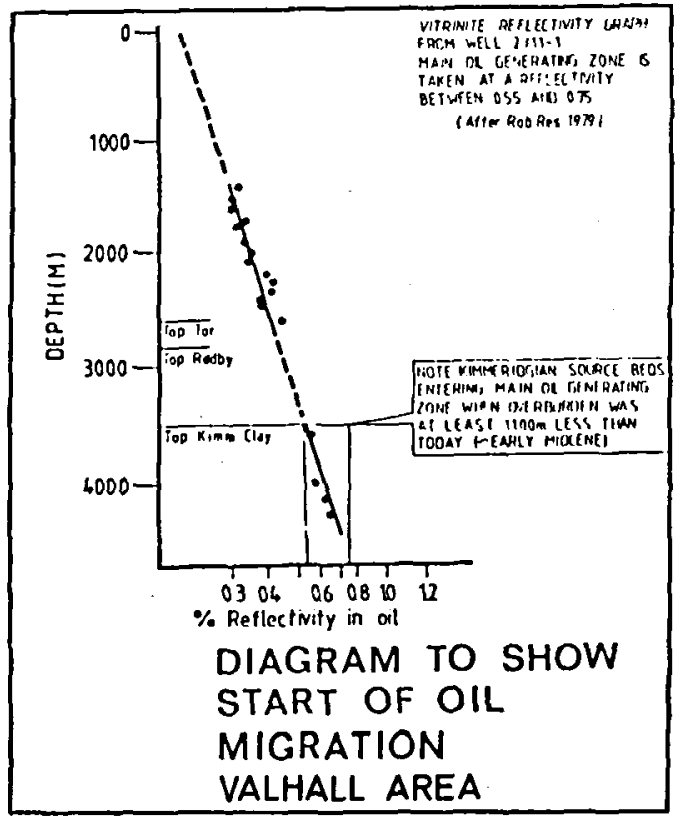

Fig. 3 


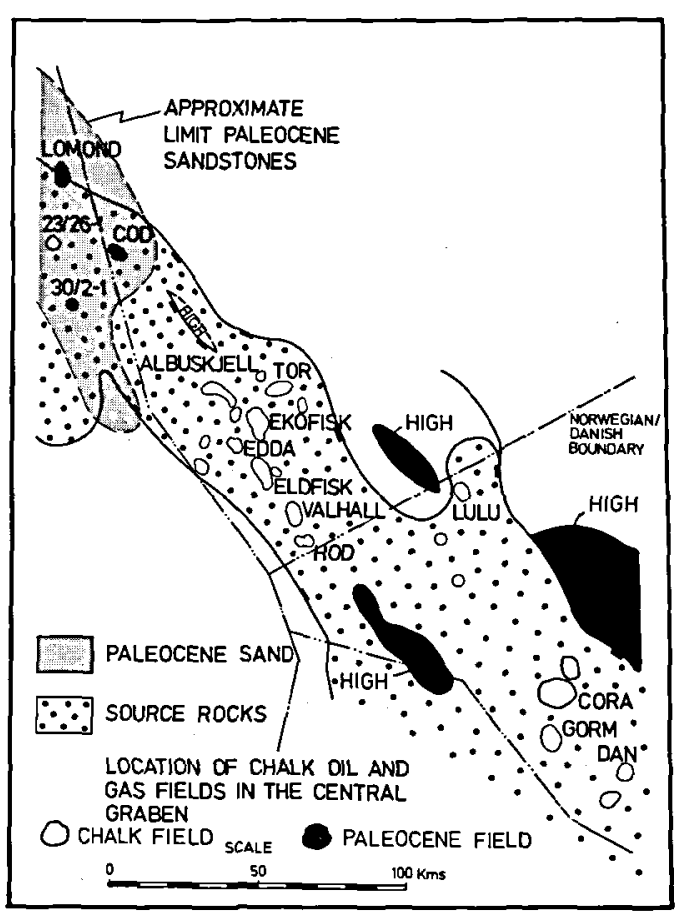

Fig. 4 ,

\section{Sedimentation and Early Diagenesis of North Sea Chalk}

It is difficult to talk about the essential sedimentary features of all the formations comprising the Chalk Group throughout the North Sea, because core study is an essential pre-requisite to understanding the sedimentation of the Chalk. In general, extensive coring only takes place where oil and/or gas is found, and therefore the data contain a bias both in an areal and stratigraphic sense. As Kennedy (1980) states, no single model explains the observed lithological sequences in the chalk oil fields since each has its own special history superimposed on the broad, basin-wide changes recognised. Although knowledge is far from perfect, some broad generalizations are now possible.

\section{Pelagic Chalk - Influence of a Rising Sea Level}

Deposition of the Chalk in the present area of chalk fields (Fig. 4) started in Cenomonian times under the influence of a sea level which, though showing fluctuations, was in an overall sense gradually rising. The warm seas of the time contained a bloom of coccolithophorid algae which released a shower of coccoliths. The minute particles released could only settle in times of complete absence of currents.

Indeed, Bromley (1979) and Hardman and Kennedy (1980) suggest that settling took place mainly in the form of whole or disintegrating fecal pellets and imply that by themselves coccoliths are too small to settle. After settling, current influences would not have a very great effect, and after the chalk ooze became dewatered on the sea bed, strong currents or "land-slips" would be needed to cause erosion. Chalk which is laid down as a result of the accumulation of a rain of coccoliths or coccolith composed fecal pellets, is here called pelagic chalk.

In the deposition of pelagic chalk the influence of a rising sea level played a critical role. At times of a high stand of sea level, land areas and the supply of terrigenous material to the North Sea area were greatly reduced. Chalks laid down at these times, notably during Upper Turonian to Lower Santonian times (the lower part of the Hod Formation) and during Campanian to Maastrichtian times (the Tor Formation) contain much less terrigenous material than the remainder of the chalk formations. These, notably the Hidra Formation (Cenomonian) and the middle and upper parts of the Hod Formation (Santonian-Campanian), never contain less than $5 \%$ insolubles. In many places the middle and upper parts of the Hod Formation are a coccolith rich marl known in the British sector of the North Sea as the Flounder Formation. (See Fig. 5).

The argillaceous chalks commonly show small scale rhythms of argillaceous and non-argillaceous chalks. In many places burrowing organisms have piped one facies of chalk into the other and in other places have blurred the contrast between the rhythms. It is presumed that the rhythmically bedded nature of the sediments was caused by a seasonal phenomenon such as a greater influx of clay during a more rainly climatic period. Bottom waters from time-to-time were stagnant and oxygen poor and when this occured the absence of bottom feeding scavengers allowed the rhythmic bedding to be preserved without bioturbational disturbance. (See Figure 6). 


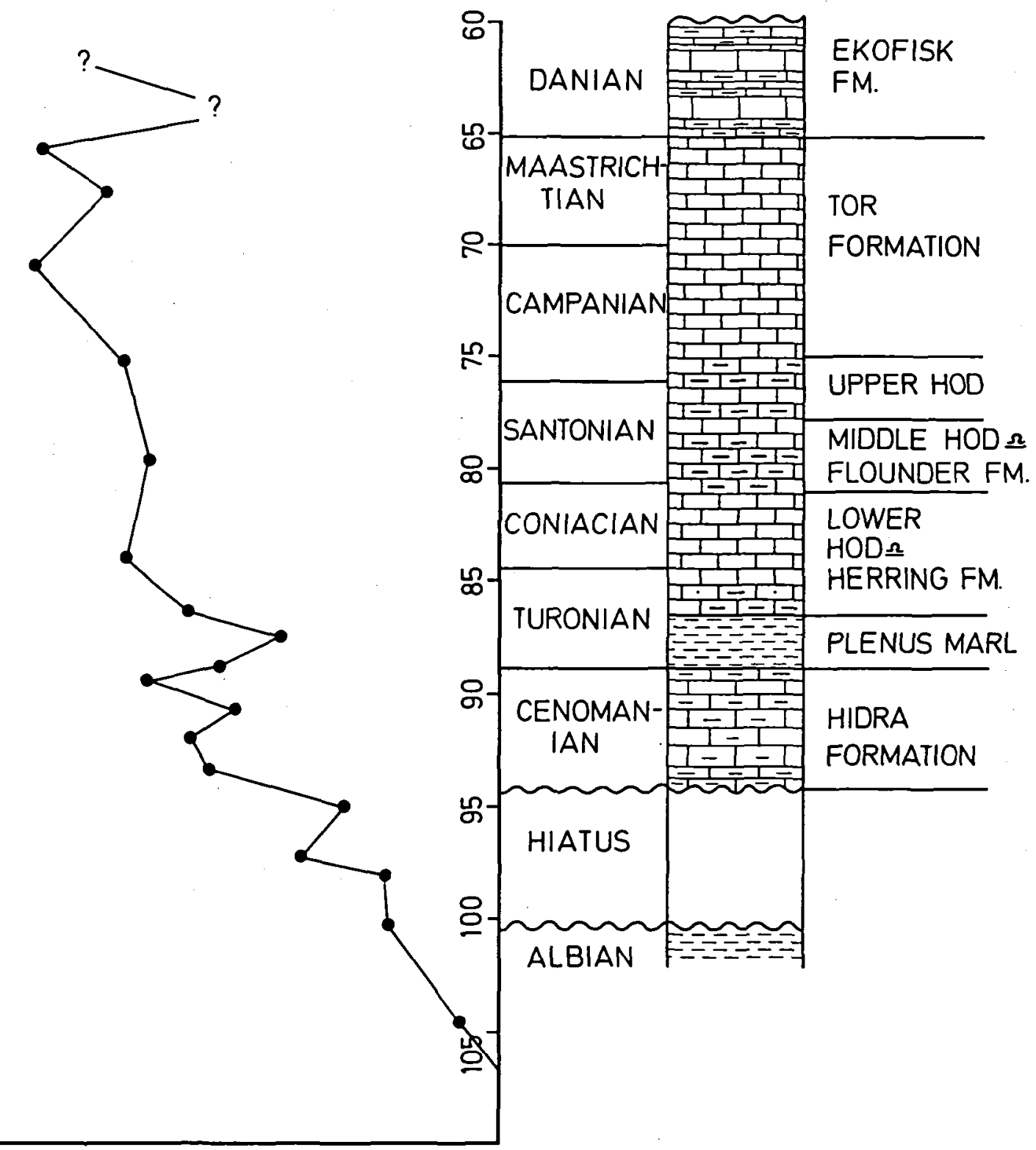

Fig. 5. The mid North Sea Chalk Group. Influence of a rising sea level (after Kennedy 1980).
Pelagic chalk is in general slowly deposited. Håkansson et al (1974) discuss rates of sedimentation for the Maastrichtian, and give a figure of $15 \mathrm{~cm} / 1000$ years, but Bromley (1979) increases this to $20-25 \mathrm{~cm} / 1000$ years. It is not known if this is for pelagic chalk or for other types, but is probably a mean rate. Pelagic chalk is likely to be more slowly deposited than the mean as will become apparent later. The slower the deposition the grater the possibilities for early diagenesis including hard ground formation. The chalks which are extensively reworked by burrowers dewater 


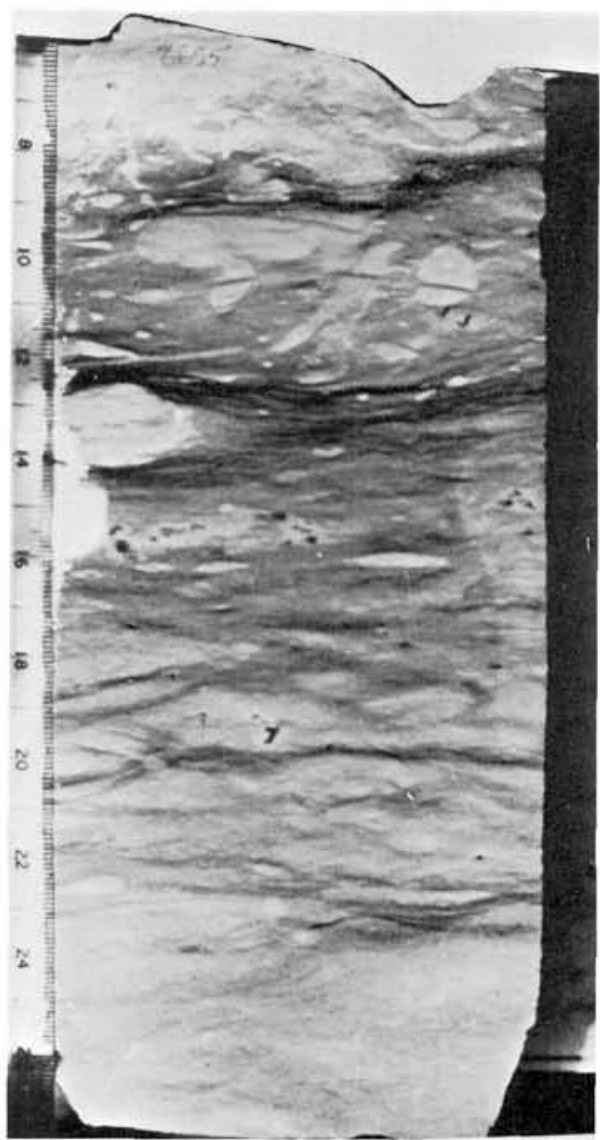

Fig. 6. An example of pelagic chalk from the Ekofisk Formation well N2 6655'. Note the extensive burrowing implying a slow rate of deposition. Where the burrowers have piped down clay-poor chalk this shows up as whiter patches. The clay-rich chalk shows much greater solution effects and appears compressed around the clay-poor burrow fill.

more quickly than those which are not subject to burrowing. Chalk ooze after accumulating on the sea bed dewaters within a few centimetres of the sea bed and porosity is reduced from a level of about $60-70 \%$ to $50-55 \%$. Burrowers not only cause further compaction of the sediment directly, but by making tubes and pipes in the soft sediment provide a large surface area for interchange of calcium carbonate from seawater into the sediment. With actual pauses in deposition, nodular beds and hardgrounds may form in which the rigid cement framework reduces the porosity to $30-35 \%$. This early lithification is not seen in argillaceous chalks, clay minerals apparently in- hibiting the formation of early cement. In contrast to very slow deposition, very fast deposition inhibits the activities of burrowers and prevents the formation of extensive early cement. Porosity of the buried sediment stays at between 50 and $55 \%$ with cement restricted to a minimal spot-welding of the grains.

\section{Redeposited Chalk}

North Sea chalk was deposited in a well marked depression or basin, the shape of which is apparent from the regional isopach, (Fig. 7). Since the chalk was deposited the basin which controlled its deposition has subsided. The broad outlines have not changed as can be seen by a comparison of fig. 7 with fig. 8, regional structural contours on top of the Chalk (after Day et Al. 1980).

The basin exerted a profound influence on chalk deposition. Under the influence of gentle basinward slopes, the semiplastic, freshly deposited chalk on the margins of the basin slumped towards the central depression. Before the studies carried out by Perch-Nielsen et al (1979), Kennedy (1980) and Watts et al. (1980) slumping within the chalk sequence in the central part of the North Sea had not been widely recognised. However, what had been recognised were that chalk slump sheets of Danian and to a lesser extent Maastrichtian age had slid down into the basin during Paleocene times, where they are now found interbedded with Paleocene claystones of the Montrose Group (fig. 9).

Kennedy (1980) in a study of the Tor Formation of the Tor Field showed that the sediment is almost entirely composed of debris flows. At the base these flows both in the Tor Field and in Danish waters consists of chalk pebbles in a fine grained matrix (fig. 10), but progressing up the Tor Formation the sequence shows increasing signs of being laid down in a semi-liquid state, with streaked out and shredded textures predominating (fig. 11). Watts et al's (1980) findings are very similar. In Hod Field, Albuskjell Field, and Tor Field calcarenitic turbidites have also been recognised. These are fine grained and consist of foraminiferal oligosteginid packstones resting on a sharp base grading upwards into a wackestone-mudstone (fig. 12). 


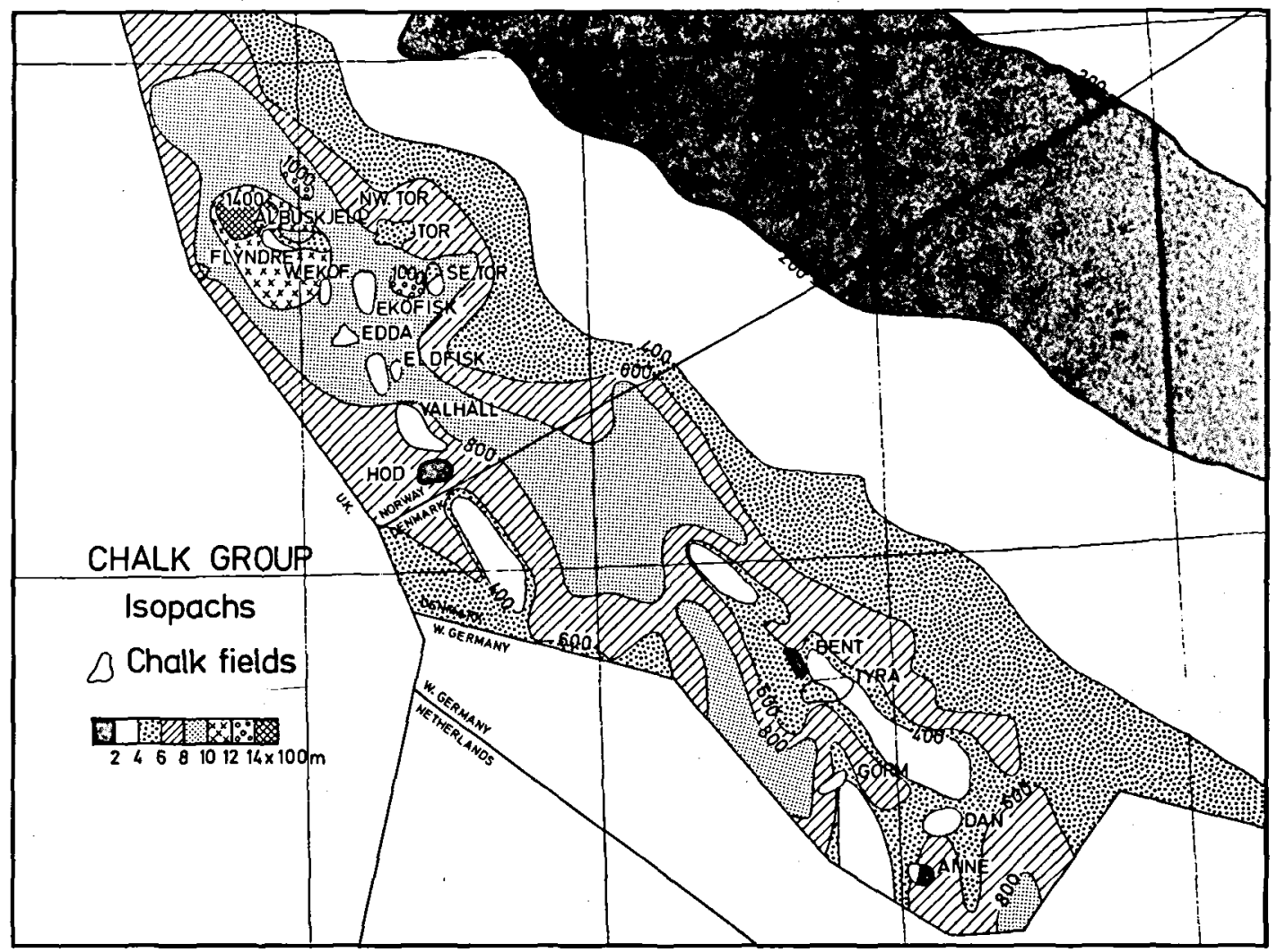

Fig. 7 .

In contrast to the Tor Formation with its abundant debris flows, the Ekofisk Formation of Danian age contains mass slides. These are difficult to recognise, but the base of the mass slide units show characteristic crumpling, and Kennedy (1980) lists seven types of deformation with which they are associated (fig. 13). Similar sliding has been recorded in well T1 in Denmark.

The anomalous nature of the stratigraphic sequence is confirmed by micropalaentology, in particular nannoplankton studies. Many of the thick chalk sequences which slid are in fact of Cretaceous age, and are now found in a Danian age sequence. The thickness of the sediment sliding into the basin can be considerable, up to tens of metres thick and hundreds to thousands of metres in lateral extent. The slump sheets may have slid several kilometres to their final resting place. From a reservoir point of view resedimentation of the chalk has been of immense significance. In the case of chalks which had been laid

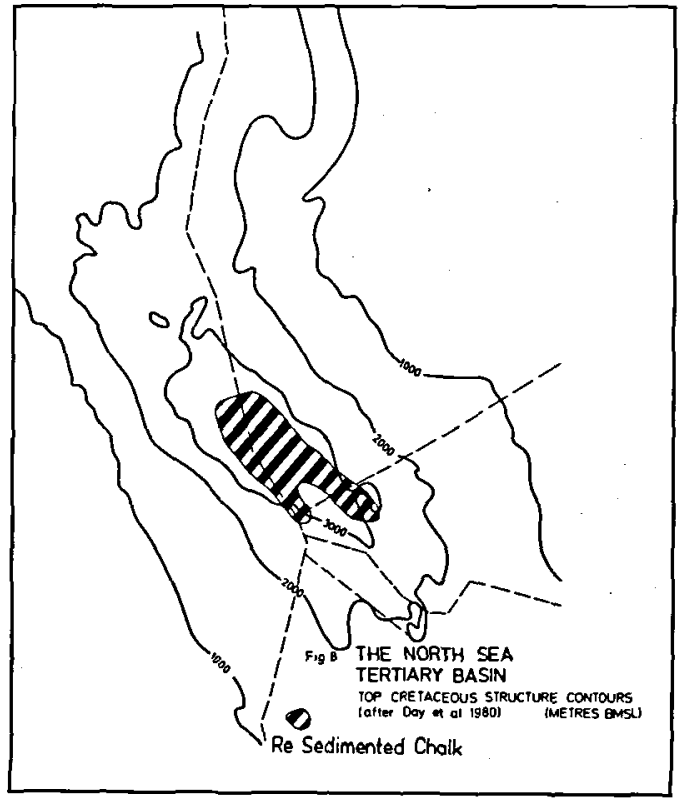

Fig. 8: 


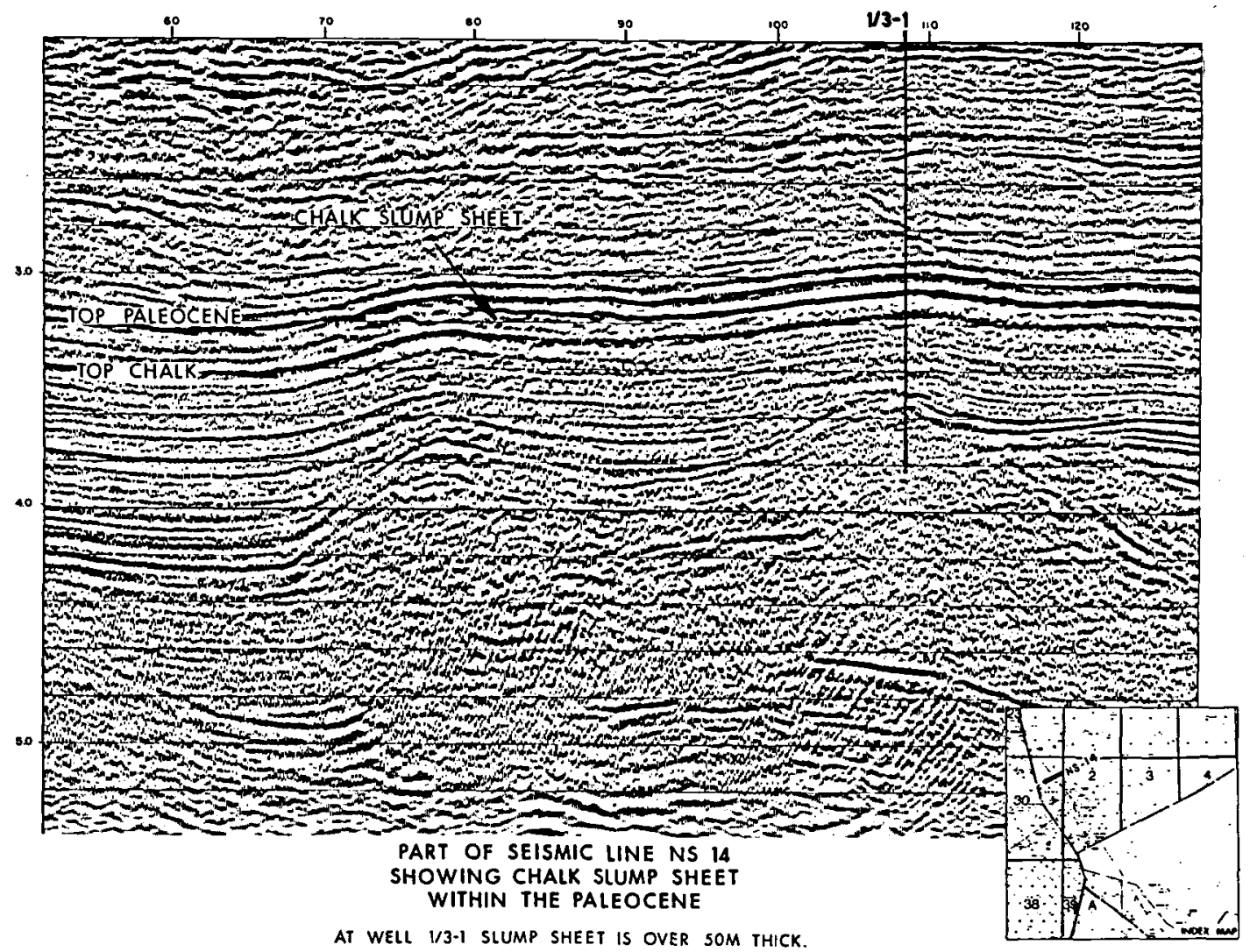

Fig. 9: Courtesy Western Geophysical.

down, and which are then resedimented by slumping, the early framework of cement is destroyed. When the chalk settles at its new site of deposition, it is a rapid accumulation. Burrowers have no or little time to act. Hard grounds do not form, and a rock with a porosity in the range $50-55 \%$ forms and is rapidly buried beneath the next resedimented deposit. Provided the sediment is clay free, the chalk has the potential to be an excellent reservoir. The mass slumps or slides are also important from a reservoir standpoint in that they allow clean non-argillaceous chalks to be introduced into a sequence of argillaceous chalks. This is of particular importance in the Ekofisk Field area where chalk of Maastrichtian age, essentially clay free chalk, has slid into a sequence of Ekofisk Formation chalk which is essentially argillaceous in nature. As we shall see argillaceous chalks, even those with relatively small amounts of clay, make poor or very poor reservoirs.

\section{Chalk "Lags"}

It has long been remarked from seismic records, that over structures which were actively growing at the time of chalk deposition, a thinning of down to one third is seen in the chalk over the crest compared to the flanks. Some small part of the thinning can be accounted for by extensional fracturing as a result of structural upgrowth, but the greatest part is sedimentary in origin.

Chalk lags are in reality sedimentary types which grade imperceptibly into other types of chalk. They are not necessarily restricted to structural crests, but as remarked before, the only evidence in the North Sea comes from cores, and these are usually taken from wells located on structural highs. Chalk lags develop because the greater part of the coccolith debris is unable to settle and is winnowed away. This occurs in any current swept area, where the heavier fraction is left behind. The most common constituents of 


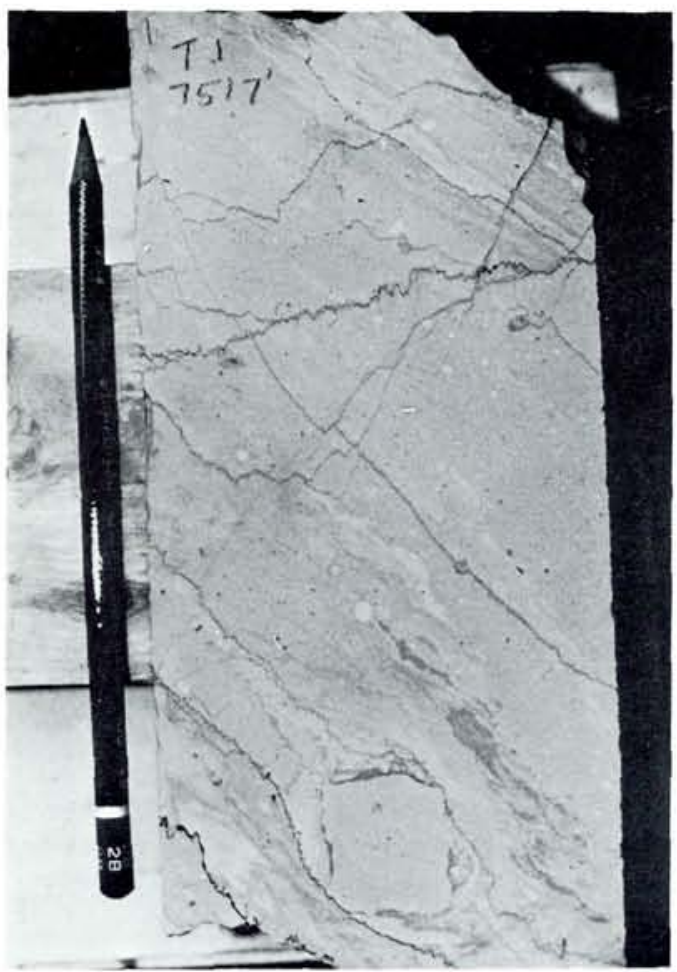

Fig. 10. A debris flow from the lower part of the Tor Formation of well $\mathrm{T} 1$ in Danish Waters at 7517.

this heavier fraction are the tests of planktonic foraminifera. Frequently these foraminifera are leached out leaving a porous and very adequate reservoir rock. Even when this does not happen, the foraminiferal rich rocks seem to have preferentially better reservoir characteristics than the poorones.

In addition to foraminifera, there is a concentration of other detrital grains. In the lower part of the Hod Formation of Valhall Field for instance, glauconite is common. At certain horizons fish scales and phosphatic nodules are common. The chalk too often takes on a nodular appearance.

Extensively penetrated by burrowing organisms, chalk lags are transitional to hard-grounds as is apparent from Fig. 14 and 15. Chalk "lags" can form good reservoir rocks provided they are clay free because they have a high content of large grains. If on the other hand they become contaminated with a relatively clay rich rock, their reservoir qualities are spoiled, the

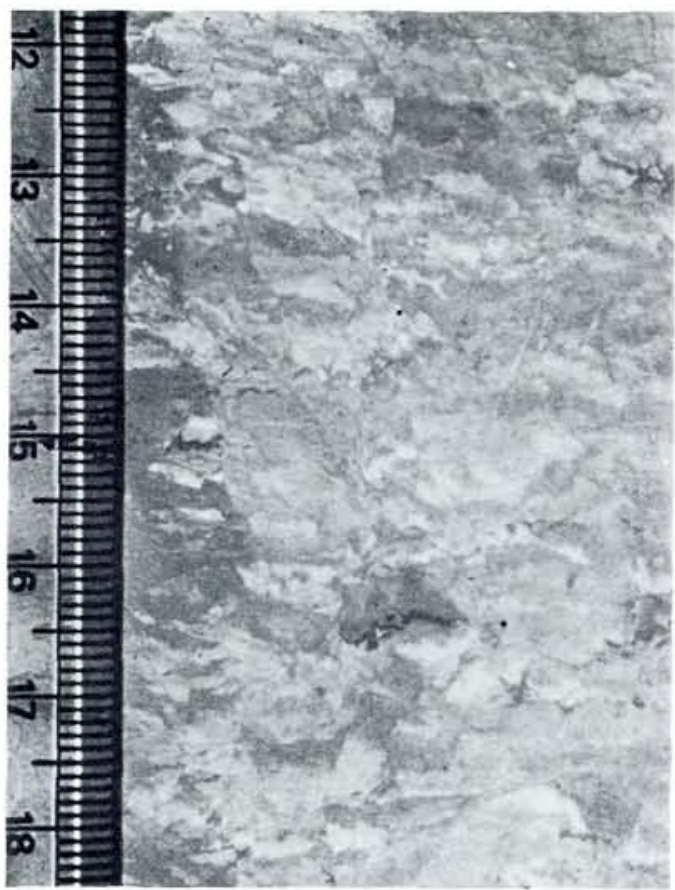

Fig. 11. "Shredded" Chalk from the upper part of the Tor Formation of the Tor Field 10504' well 2/5-1 (after Kennedy 1980). The slump deposits of the Tor Formation show the effect of a rising sea level in that early deposits are probably short travelled debris flows, but these are followed by sediments which show the results of deposition from increasingly liquid masses. The contrasts between fig. 10 and 11 illustrates the point.

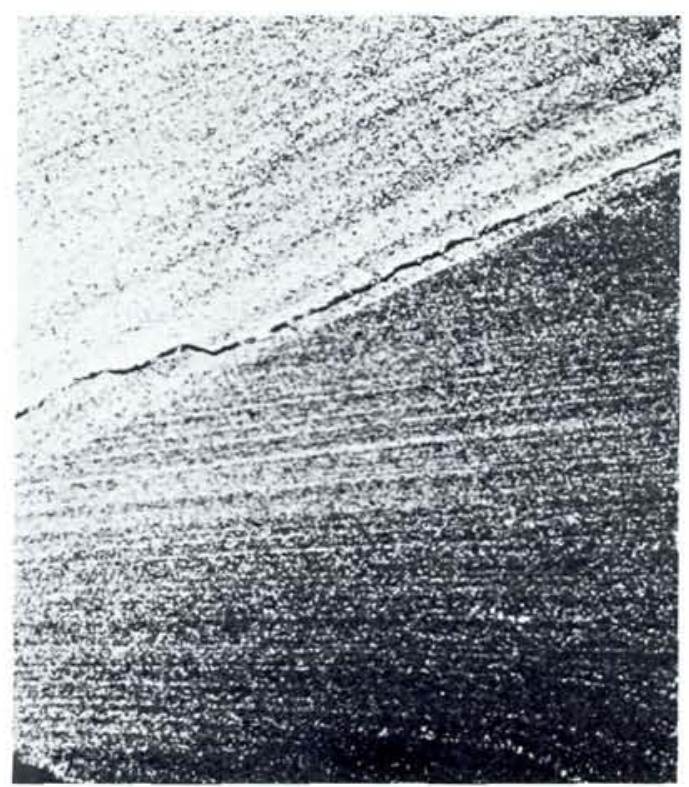

Fig. 12. Negative print of a calcareous turbidite, Lower Hod Formation, well 2/11-2, Hod Field (after Hardman and Kennedy). 


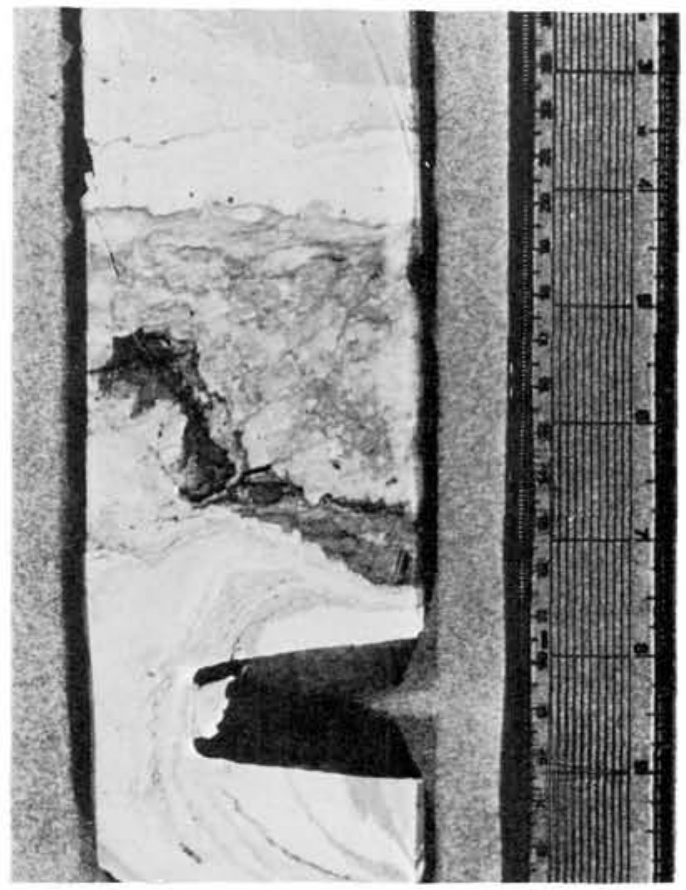

Fig. 13. Base of slump sheet Ekofisk Formation, well 2/4-8AX, Tor Field. Note chaotic breccia above lowermost slump fold (after Kennedy 1980).

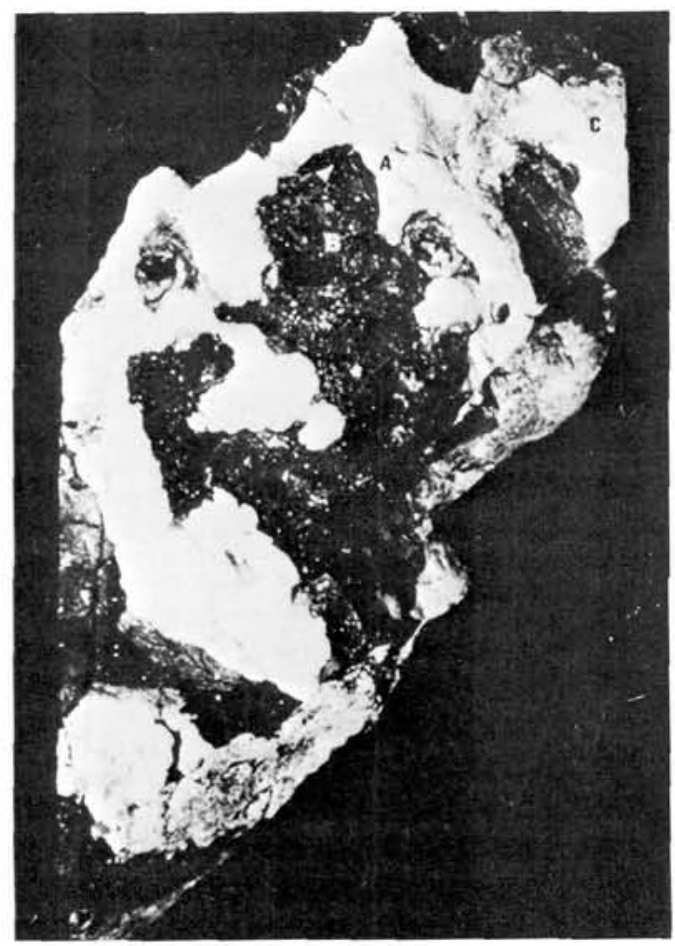

Fig. 14. A highly burrowed chalk from well $2 / 11-3 \mathrm{~A}$ Hod Field. The matrix is well cemented, but the burrow fill is much more porous and oil stained. The rock is transitional to a hard ground.

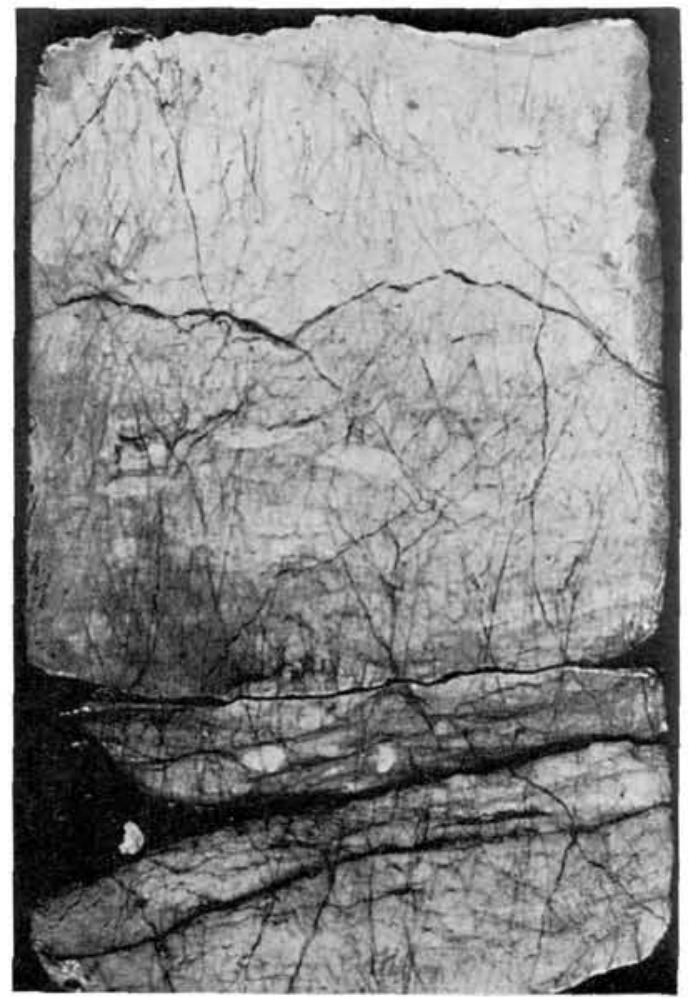

Fig. 15. Valhall Field. Better reservoir quality rock consisting of a lag of chalk pebbles and heavier grains.

poor quality chalk acting as a contaminant which later on during diagenesis causes closing of pore throats through grain crushing and re-deposition of calcite through pressure solution. They are also poor reservoirs if too extensive an early cement framework forms whereby the rock is a firm or hard ground.

\section{"Marginal Facies" Chalk}

The term "marginal facies" is here used to imply a chalk which shows clear signs of having been laid down in moderate water depths. So far no "marginal facies" chalk is known as a reservoir in the Norwegian sector of the North Sea, but there is no reason why such a type should not prove to be a reservoir in the future. It is likely that the Dan Field chalk in Denmark is of this facies.

The Bryozoan chalk of the Maastrichtian of Stevns Klint, Denmark is an example of one type of marginal facies. The distinction between chalk 
"lags" and marginal facies may prove difficult in practice, but in concept at least is clear. A marginal facies develops in relatively shallow water over a considerable areal extent while a chalk lag can form in much deeper water, but is restricted areally and often stratigraphically to a structurally high area.

Marginal facies chalks are expected to be clay poor and to contain the remains of such organisms as bryozoa, echinoids and bivalves which flourish at moderate water depths. Because the sediment is essentially clay free and contains coarse debris, although calcite mud supported, reservoir characteristics of marginal facies chalks are expected to be favourable.

\section{Diagenesis}

\section{General Considerations}

As has been noted earlier, chalks were deposited predominantly in the form of low magnesian calcite, a remarkably stable mineralogy which they still retain. Of the other components only the clays played a significant role in diagenesis, and their presence or absence is a key factor in understanding the post-burial history of the sequence. The presence or absence of aragonite is not considered significant, since most of the material composing chalk is magnesium poor.

After deposition, the calcite mud was dewatered by both compaction and burrowing, so that its water content dropped to $50 \%$ or less a few tens of centimetres below the surface. (Hardman and Kennedy 1980). At the same time, disturbance and ingestion by burrowers broke up complete coccolith scales and coccospheres, but there is surprisingly little evidence of actual biogenic corrosion of grains. With very rapid deposition such as occurs in the chalks deposited by turbidity flows, or by falling out from suspension, burrowing is incomplete. Meiofauna can not function and the deep burrowers are not able to completely churn the sediment. Primary lamination remains and the formation of early cement is minimal and restricted to spot-welding of the grains.

With pauses in deposition, pure chalks underwent very early cementation to give "firm"

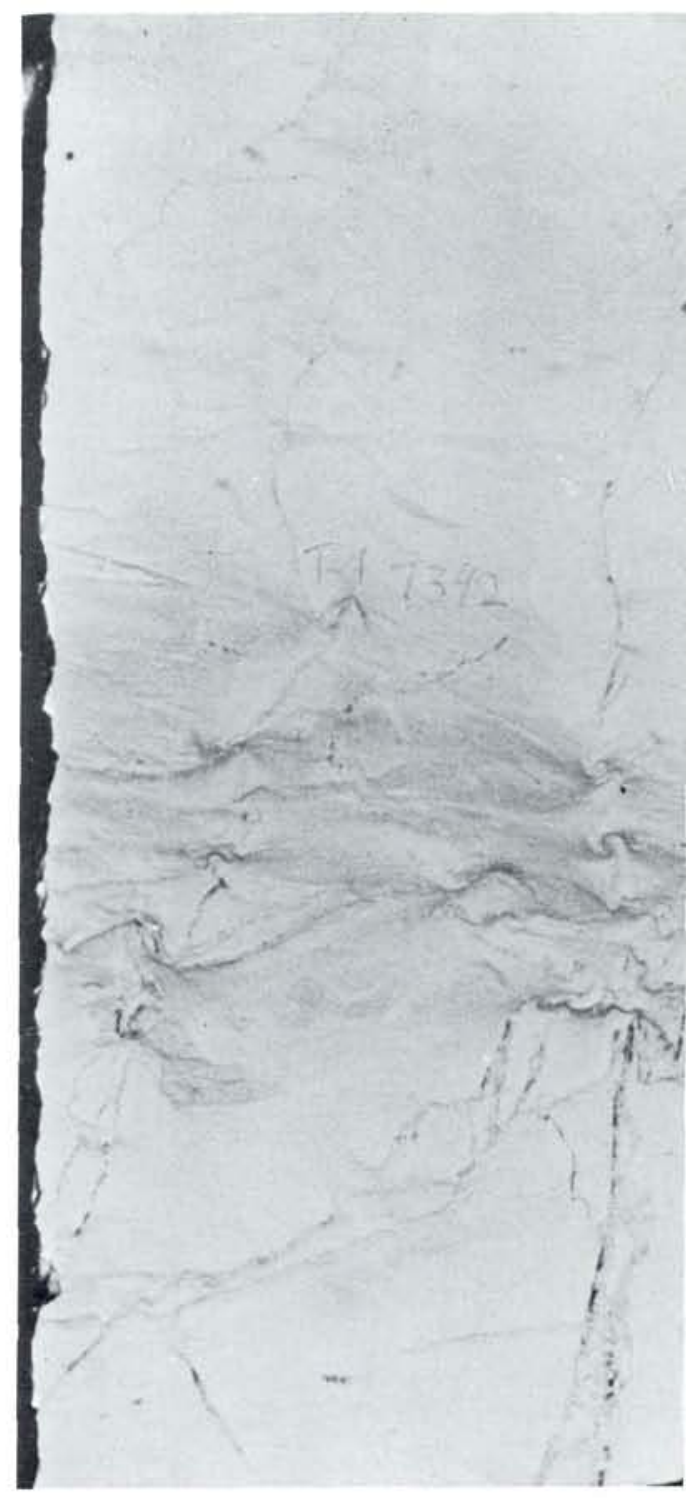

Fig. 16. Evidence that an early rigid framework does not form in clay-rich chalks. Fractures, one of which is clearly seen on the right-hand side of the photograph, are transformed into a zone of isoclinal folding in the clay rich middle part of the core. Having passed through this zone, fracturing is resumed. The specimen is from the Ekofisk Formation of well T-1 in Danish waters.

grounds, nodular units and eventually hardgrounds, which probably formed in hundreds to thousands of years in the top meter or so of the sediment columns. Growth of cement crystals from seawater produced a rigid framework of grains, strong enough to be reworked as intra- 

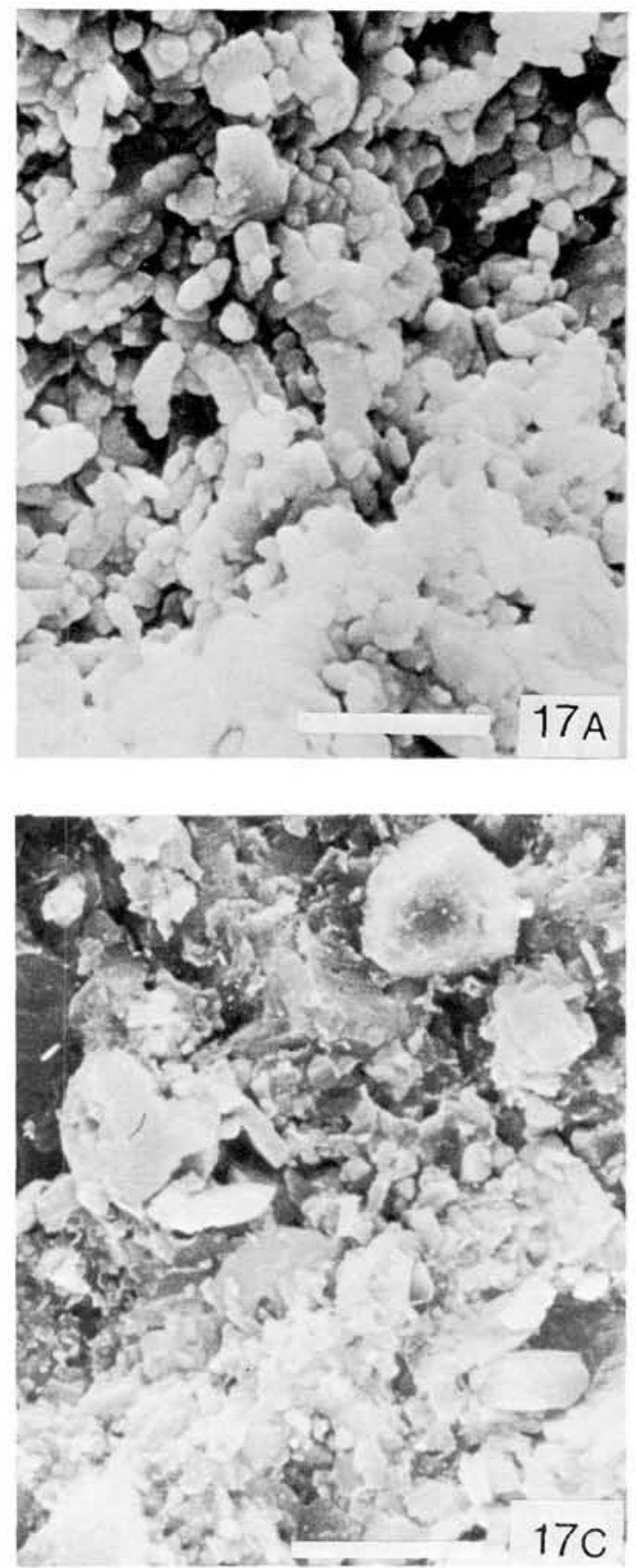

Fig. 17. Scanning electron micrographs of rock types from Valhall Field (after Hardman and Eynon 1977).

These types refer to figure 20 . Note the corrosion of the coccolith fragments in type A, the overgrowths on the coccoliths in types $\mathrm{B}$ and $\mathrm{C}$ and the clay minerals in types $\mathrm{C}$ and $\mathrm{D}$. Average
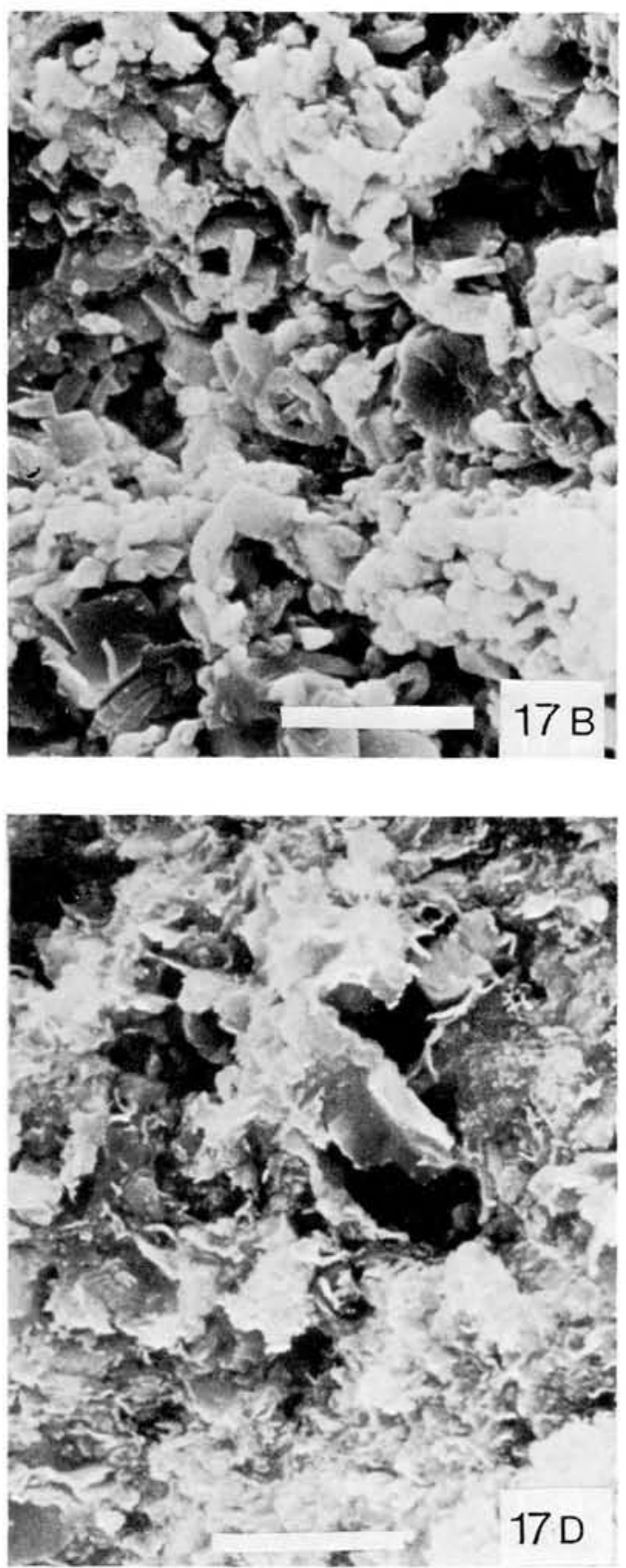

clay content is less than $5 \%$ in $\mathrm{A}$, less than $10 \%$ in $\mathrm{B}$, somewhat over $10 \%$ in $\mathrm{C}$ and much more than $10 \%$ in D.

$\mathrm{A}, \mathrm{B}$ and $\mathrm{C}$ have reservoir qualities. D is not a reservoir. Length of $\mathrm{bar}=5 \mu \mathrm{m}$. 


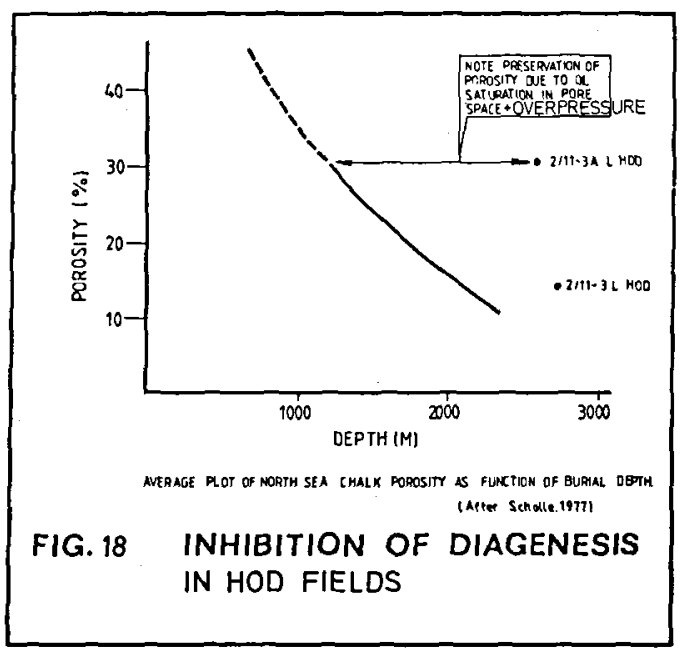

clasts, and with porosities reduced from $50 \%$ to between $45 \%$ and $30 \%$ depending on the degree of early cementation introduced. As is demonstrated by fig. 16 such early lithification is not seen in argillaceous chalks, the clay minerals apparently inhibiting growth of early cement as point contacts between carbonate grains failed to develop.

Some few meters below the sea bed the porosity of a clean chalk ranged from a maximum of about $50 \%$ to a minimum of $30 \%$ depending on the depositional history. In a pure chalk, three processes affected further loss of primary porosity: increasing weight of overburden (generally related to depth of burial), geothermal gradient and tectonic stresses. Only the first of these is of general importance in chalk fields of the North Sea. As pressure increased, there was renewed solution at point contact, and smaller crystals went into solution, as did certain groups of foraminifera. Because the pore fluids of the chalk were originally marine, they contained a high concentration of magnesium. Magnesium ions "poison" sites of nucleation, and pore fluids may have become locally supersaturated. As local conditions changed, this carbonate was precipitated as overgrowths on coccolith debris or as microspar crystals in voids; these processes were probably insignificant at burial depths of less than $300 \mathrm{~m}$, and produced not more than $5 \%$ cement by $1000 \mathrm{~m}$, but normally would result in complete lithification and loss of porosity by $2-4000 \mathrm{~m}$ burial depth (Scholle 1974, 1977). That this did not occur in the chalk reservoirs is due to both overpressuring and oil emplacement (figs. 17-18).

As depth of burial increased, the solution transfer at submicroscopic level became manifest at a gross level, in the form of first solution seams, followed by the development of stylolites and residual solution seams. These are still forming today. These structures point to the massive transfer of carbonate in solution; much of the loss of porosity in chalks can be attributed to the redistribution of carbonate within the rock column without injection of additional material from elsewhere.

\section{The Importance of Clay}

When chalks contained appreciable (i.e. more than 5\%) amounts of clay, the processes outlined above were drastically modified. This was initially expressed during the compaction phase. As the chalky ooze was compressed, clay flakes rotated normal to the stress and the degree of compaction was thus greater than in a pure chalk at the same burial depth, although the rock itself retained its plasticity (fig. 16) because the clays had prevented the formation of the initial open framework of the rock. It can now be seen that the early-formed open framework is of fundamental importance in determining the reservoir potential of chalk. Further compaction ensued; weakly-bonded coccoliths were crushed and mechanical breakup reduced porosity still further. As a result of breakup, coccolith debris underwent size reduction and was immediately susceptible to more rapid solution. The clay minerals furthermore absorbed magnesium ions which might otherwise have inhibited carbonate precipitation, so that when there was redeposition as cement and overgrowths, this was to a much greater extent than in a pure chalk at a comparable depth of burial.

This is graphically illustrated in the cyclic clay-rich and clay-poor parts of the cycles in the middle and upper Hod Formation, where adjacent chalks and marls show quite distinctive diagenetic fabrics. As clay content increases, the rock shows, paradoxically, more evidence of solution and reprecipitation (fig. 6). 
Many S.E.M. pictures show clear evidence for the growth of authigenic, neoformed clays. These will have had the same effect as the detrital clays in the sequence, while their growth in voids and pore throats also reduced permeability (fig. 17).

\section{Corrosion of Coccoliths}

Corrosion of coccolith debris is widespread in all formations studied. At first sight, this appears to be a mechanism for enhancing porosity and permeability. It is not, however, easy to determine whether this corrosion occurred when the coccolith was ingested by some element of the zooplankton of the time, on the sea bed, early or late in diagenesis. Indeed, scanning across a few millimetres of sample shows that corrosion and redeposition, overgrowths and cement and void filling crystals occur side-by-side in the same sample (fig. 17).

\section{The significance of early oil migration}

Chalks were originally buried in contact with sea-water, and there is no evidence whatsoever in the fields examined to date, that these marine pore fluids were ever replaced by meteoric waters as a result of subaerial exposure. All the erosion surfaces present in the sequence were undoubtedly marine. The fluids may, however, have suffered alteration, especially an increase of magnesium ions which would inhibit precipitation of calcite cement and overgrowth. Dolomite (or Dolomite Pseudomorphs) occur at the top of the Ekofisk Formation (and are indeed known elsewhere in the North Sea - Hancock and Scholle 1975) and may indicate local concentration of magnesium ions, perhaps accounting for patchy porosity preservation.

These effects are, however, insignificant when compared with those of over-pressuring and oil emplacement, for, when overpressuring occurs and to an even greater extent when this is accompanied by oil emplacement, diagenesis of the chalk is very significantly reduced.

Studies on the underlying Upper Jurassic source rock shales by many authors in the area confirm that generation of oil commenced in the Upper Eocene and continues to the present day (see e.g. Hardman and Kennedy 1980). At the time of the start of oil migration, the average depth of burial of the top chalk in most fields is estimated to have been about $1000 \mathrm{~m}$ to $2000 \mathrm{~m}$. It follows and is confirmed by drilling that outside the area where overpressuring and oil is present in the chalk matrix, a very rapid increase in diagenesis has occurred, porosity being significantly lower. For instance in $2 / 11-3 \mathrm{~A}$ where the Lower Hod is oil-bearing, a porosity of over $30 \%$ is registered. In the nearby well, $2 / 11-3$, where the Lower Hod is oil-free, porosity never exceeds $20 \%$ and averages approximately $15 \%$ (see fig. 18). Accumulation of hydrocarbons in the matrix of the chalk inhibit diagenesis in two ways. From a physical standpoint and of primary importance because the chalk reservoirs of the North Sea are all overpressured up to the extent that the pore pressure is sufficient to support partially or wholly the overburden, stress and mechanical compaction are reduced and pressure solution at grain contacts does not take place. The reason for the overpressuring has already been explained above.

From a chemical standpoint, when the pore water between the coccolith fragments is replaced by hydrocarbons, there no longer exists a medium for the transfer of calcium carbonate from the points of contact of the fragments into the unstressed void spaces.

In order to have an oil column in the chalk in the first place, fracturing is essential, as oil is unable to pass from the Upper Jurassic to the Upper Cretaceous without a network of fractures.

Early movement of a structure or drape of the Chalk over the structure will cause fracturing, and the vertical relief must be such that the oil column will be long enough to exceed the entry pressure of the pore throats in the chalk. These conclusions are confirmed by observation: most oil-bearing chalk structures grew during deposition of the chalk as witnessed by thinning of the Chalk over their crests, the movements in general continuing into the Tertiary. Structures with low vertical relief, even when favourably located with regard to source beds, exhibit wet chalk or chalk with minimal oil-saturations. High oil-saturations only occur in high relief structures. In these the pressure of the oil column becomes so great that in the crestal region, the overlying seal is often broken down and hydrocarbons (mainly gas) ac- 
cumulate in the beds above the chalk reservoirs giving rise to the well-known disruptive interval on seismic records. It is, furthermore, confirmed in these cases that the reservoir pressure is usually sufficient to support the overburden.

In conclusion, early overpressuring with or without oil migration is an essential pre-requisite for the preservation of reservoir quality chalk. Once diagenesis has taken place, despite the fact that oil may be available to migrate into the structure at a later time, the rock characteristics are then such that oil is no longer able to enter the pore space.

\section{Fracturing}

Fracturing of the chalk reservoirs is of critical importance as has already been explained. In addition, once the oil has migrated into the reservoirs, the matrix permeability is so low (generally less than $3 \mathrm{md}$ and often less than $1 \mathrm{md}$ ) that it is only as a result of the fractures that commercial flows can be obtained from the chalk (fig. 19).

A study of fracturing shows that it is most intense where the chalk is thinnest and tends to be concentrated within the structurally-weak chalks. These are in general the weak, high-porosity chalks, but there is no direct relationship between porosity and intensity of fracturing. Most fracturing is subvertical but other orientations also exist:-

- F1 and F2 common shear fractures of the extensional type, vertical and $15^{\circ}$ from vertical.

- F3 and F4 a second subordinate set of shears at $37.5^{\circ}$ and $45^{\circ}$ from vertical.

- F5 and F6 tension gashes associated with two recognised stylolite trends, horizontal and $15^{\circ}$ from the horizontal, mainly developed in the more indurated chalks.

Fracturing is related to the continued growth of the structure after early consolidation of chalk. In the crestal region, as is to be expected from consideration of the geometry, intensity of fracturing decreases downwards from the Chalk/Paleocene shale interface. Where fracture intensity is greatest, as in the high porosity Tor Formation, the chalk is cut into matrix blocks of gravel size (1-2 cms) (se fig. 15). Nevertheless, the addi-

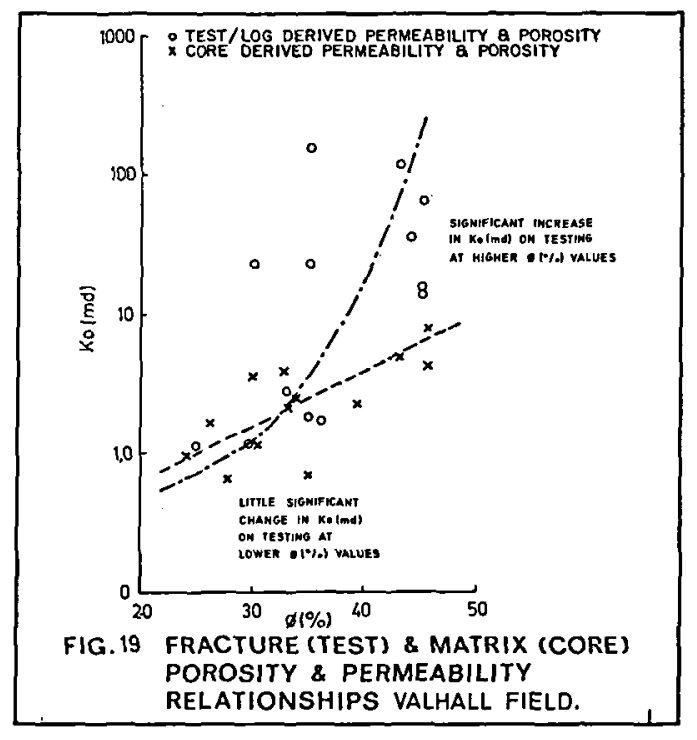

tional porosity resulting from fracturing is extremely low and under no circumstances is expected to exceed $0.4 \%$ of the porosity even in the most intensely fractured intervals. Within the Hod Formation, although there are some intensely fractured intervals, the matrix blocks in general are much larger than those of the Tor Formation and probably range from $5 \mathrm{~cm}$ in the most fractured intervals to several meters in the low porosity, clay-rich chalks.

Fracture intensity is also related to position on the structure and the total thickness of the Chalk. In general, fracturing is at a maximum where uplift is at a maximum and the total Chalk interval is at a minimum. In such areas, total strain and hence fracture-intensity are at a maximum.

\section{Conclusions - Controls on Chalk Reservoir Rock Quality}

\section{Clay}

The amount of clay in the chalk, whether primary or secondary, is the factor of greatest importance in determining whether chalk has the capability of forming a reservoir rock or not. Hardman and Eynon (1977) presented the result of analysis of many chalk samples from different stratigraphic 


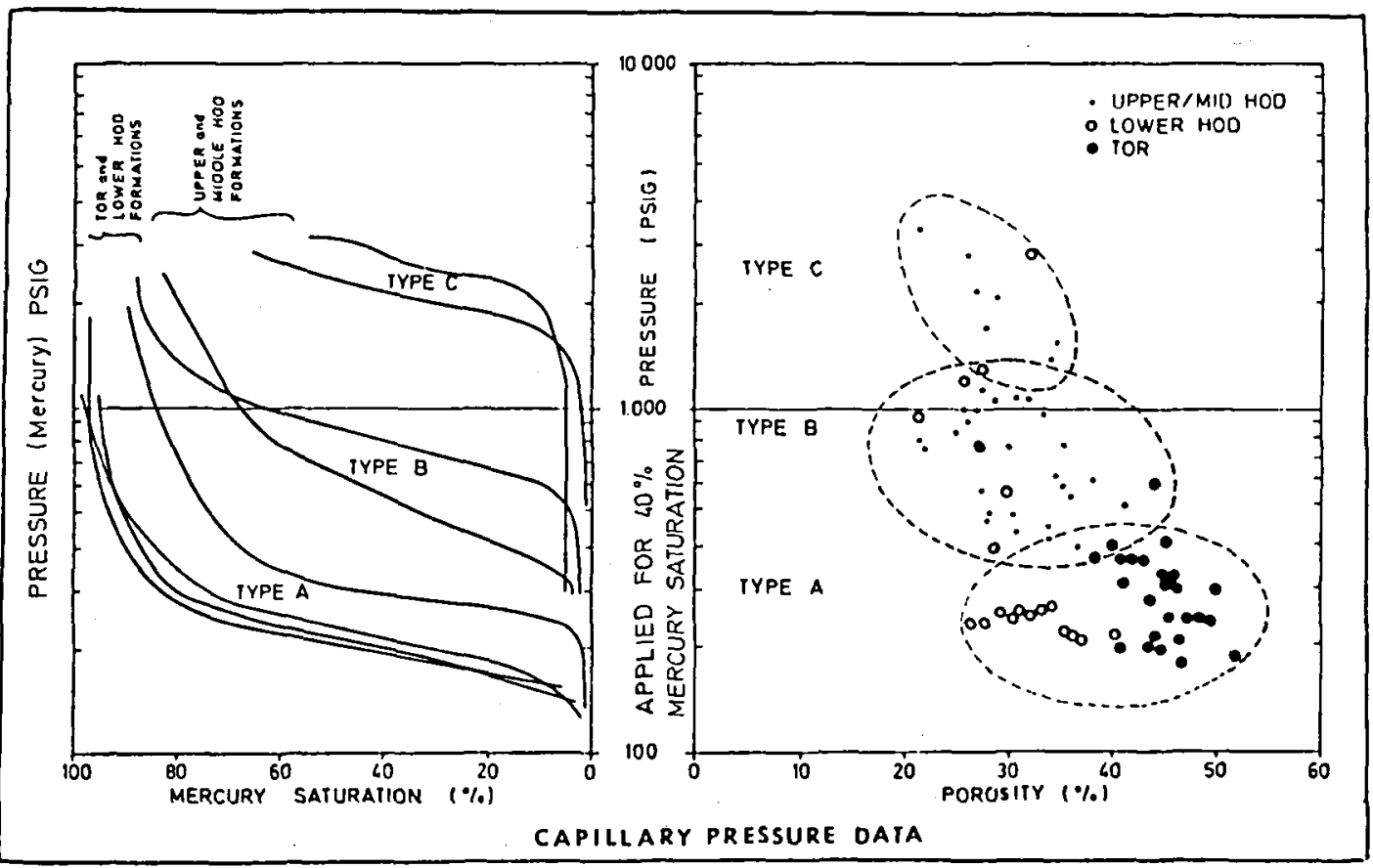

Fig. 20. For illustrations of the rock types see Figure 17. From the diagram it would appear that the Tor Fomation and the Lower Hod Formation should have the same reservoir characteristics. That they do not may be a result of the Lower Hod Formation being composed of particles of a smaller size. Valhall Field (Hardman and Eynon 1977).

horizons from the Valhall Field and on the basis of capillary pressure data were able to divide the chalk into four groups, three with reservoir properties and one without (fig. 17 and 20). They did - not analyse clay as such only total insolubles, but they found that total insolubles in the best reservoir quality rock, type $A$, never exceeded $15 \%$; in the next quality type $B, 30 \%$ and in the poorest rock that behaved as a reservoir (i.e. showed any oil saturation) $35 \%$. Furthermore, in general, of the total insolubles only about one third are clay minerals, the remainder being silt size or smaller quartz particles which have little effect on the reservoir quality. In general, it can be said that rocks which contain no more than $5 \%$ clay minerals have the potential of forming good reservoirs, from $5 \%$ to $10 \%$ fair reservoirs and over $10 \%$ only poor reservoirs are possible. It has been empirically observed that the less the clay content the better the reservoir and as has been remarked earlier, the amount of clay in the Chalk can be closely correlated with sea level changes.

Where other factors are either absent or of

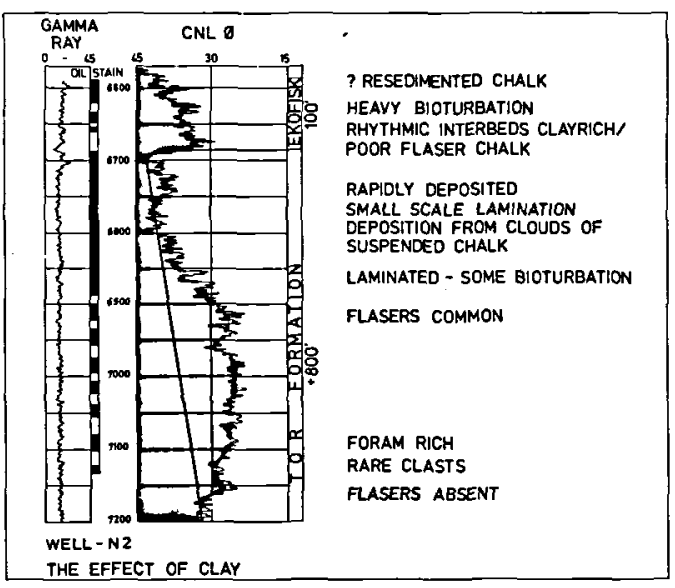

Fig. 21. Well N-2 was drilled in an area where the chalk was rapidly thickening. The straight line connecting the upper and lower parts of the Tor Fomation is estimated to represent the reduction in porosity which results from an increase in pressure the reduction in porosity which results from an increase in pressure and a decrease in oil saturation with depth. The reduction in porosity recorded in the well to the right of the line represents an increase in clay content during a temporary lower stand of sea level during late Campanian/early Maastrichtian times. 


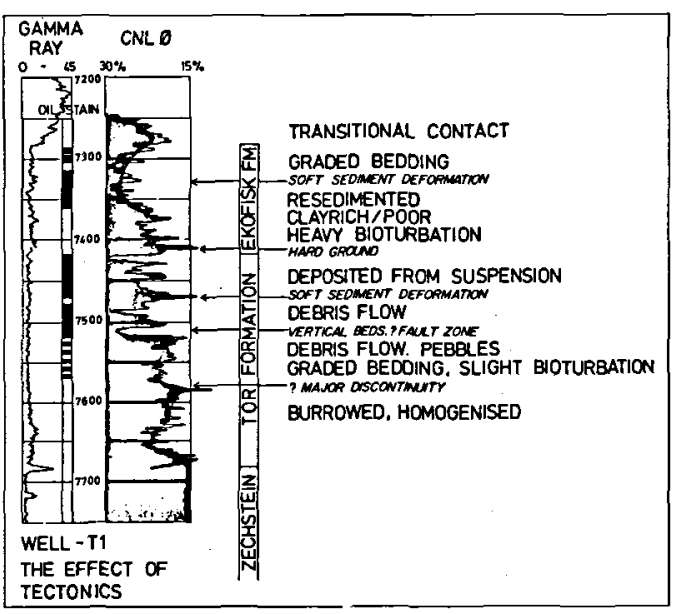

Fig. 22. Well T-1 was drilled in the deepest part of the chalk basin. Reservoir quality in the Tor Formation would have been very good, but for the contemporaneous structural movements which caused much of the reservoir sequence to literally slide of the growing structure.

only minor importance, the effect of clay is most clearly seen. A good example is well $\mathrm{N}-2$ in Danish waters (fig. 21-22).

A gradient line connecting the clean reservoir near the base of the Tor Formation to the clean reservoir at the top of the Tor Formation gives the expected deterioration of the reservoir due to decrease in overpressuring and oil saturation with depth. A visual examination of the chalk which shows significantly worse reservoir quality than is indicated by this line, reveals that the chalk is rhythmically banded with slightly clay rich layers alternating with clay poor layers and flaser structures common in the clay rich layers. The development of porosity in the Tor Formation of this well is seen to bear a strong positive correlation to the amount of clay present in the rock. Furthermore, the porous, clay-poor rocks show a far greater intensity of fracturing than the clay rich rocks. It is concluded that in N-2 clay is the dominant control on reservoir quality.

Paleogeographic setting; tectonic history, rate of sedimentation and degree of early diagenesis

In the case of clay-free chalks, other factors become of importance in determining reservoir quality. Among the most important appears to be the degree of early cementation. This in turn is a function of the rate of sedimentation, and the intensity of burrowing. Early cementation develops in sequence from the spot welding as reported by Mapstone (1975) in the Tor Field to the extensive hardgrounds discussed for instance by Kennedy and Garrison (1975). The amount of early cement is a function of several factors among which rate of sedimentation is the most important. Fast deposited chalks have minimal early cement. Slowly deposited chalks are extensively cemented grading into hard grounds.

After early cementation, diagenesis at depth appears to obliterate porosity equally in chalks with extensive and with minimal early framework cements. As an example, if after early diagenesis two chalks have porosities respectively of 40 and $50 \%$, these when buried to say $2000 \mathrm{~m}$ will have porosities of $30 \%$ and $40 \%$ respectively; That is, the rate of porosity loss is the same for both samples, the only difference being the amount of early cement.

If redeposition of chalk leads to a break up of early cement as when a dewatered chalk slumps and passes into a debris flow or suspension, then early cement breaks down and because of rapid deposition may not be able to form to the same degree. Consequently redeposited chalks are often among the better reservoir chalks. However, if the redeposited chalks contain well cemented clasts (which have poor reservoir quality) the whole rock may prove to be an average or poor reservoir.

On a growing structure, crestal wells often turn out to have relatively poor reservoirs because of the slow rate of sedimentation over the crest and because newly deposited chalk will move down-hill on very gentle slopes. T-1 in Denmark is a well which shows very strongly the results of deposition of chalk reservoirs over a strongly positive structure (fig. 22). Some of the beds are vertical and fracturing and faulting are common. The Tor Formation shows very strong evidence of resedimentation, presumably of a regional nature, and the Ekofisk Formation shows soft sediment deformation at many horizons suggesting that the sequence may consist of a coalescence of allochtonous sheets. Despite seismic evidence of thick chalk on the flanks of the structure and the indirect evidence provided by the beds which slumped into the area, reservoirs in T-1 are gen- 
erally thin and except at a few horizons poor. This is a result of the very strong upgrowth of the structure during sedimentation. Reservoir rocks slid off the structure and much early cement was introduced into the beds which remained reducing the reservoir quality very significantly.

Size of coccolith and other particles

As the coccolith assemblage changed throughout time it would be expected that the best chalk reservoirs would be comprised of the coccoliths which had the largest particles. In practice the effect of clay on reservoir quality is so much more important that this effect is hard to quantify. Perhaps the main difference in the Valhall and Hod Fields between the lower Hod reservoir and the Tor formation reservoirs which are both clay free, is the size of the coccolith fragments composing the reservoir. If this is not the case, it is very difficult to account for the difference in reservoir quality between them.

The effect of larger particles has already been mentioned. The presence of large numbers of foraminifera in chalk "lags" has a very beneficial effect on reservoir quality especially as often happens the forams are leached out. Bryozoan and shell debris can have the same effect if they are sufficiently concentrated. In general, though, larger particles appear to have only a purely local, that is restricted, effect on reservoir quality.

Early oil migration, fracturing and depth of burial

The timing of oil migration and the depth of burial at which this occurs is clearly of critical importance. Burial diagenesis sets in generally when chalks reach 1000 metres. Should oil migration start at this time and more importantly, oil emplacement in the reservoir, implying a pressure slightly in excess of hydrostatic, porosity will be preserved at the top of the reservoir at more or less the same level as existed when the rock was some few meters below the sea floor. Valhall Field is a good example with porosities in the Tor Formation in excess of $50 \%$ common. The later that oil entry of the reservoir takes places the lower the porosity will be preserved. As has al- ready been discussed, for the oil to reach the reservoir in the first place implies fracturing. Fracturing is helpful in that the pressure effects and migrating oil are transmitted to the whole area of the structure simultaneously. Furthermore, it is unlikely that commercial flow rates could be achieved without fracturing.

\section{Other Late Stage Diagenetic Effects}

D'Heur (1980) drew attention to the fact that porosity reduction in chalks is accompanied by a redistribution of calcite in the reservoir with a concommittant loss of thickness. This is largely achieved by stylolization. Stylolites often follow fractures. They can if remaining uncemented and unblocked greatly add to reservoir quality by acting as conduits for flow.

In addition to redistribution of calcite, redistribution of silica also occurs leading to the formation of the well-known nodular and tabular cherts. It has been found that below the effective oil/water contact, silica is deposited in the pore space in many chalk reservoirs, causing complete blockage and effectively sealing the oil into place. This does not occur in the oil zone and is of importance only to reservoir mechanics.

Acknowledgements. This paper is partly based on studies of the Valhall and Hod Field, published with the kind permission of Amoco Norway Oil Company and its partners Amerada, Texas Eastern and Noco.

I would also like to thank W. J. Kennedy for all the inspiring work he has carried out on the chalk, and for the assistance he provided in analysing the chalk of the North Sea.

My gratitude is due to D.G.U. and in particular Arne Dinesen who suggested this paper and made available cores from $\mathrm{N}-2$ and T-1 wells. Erik Nygaard assisted in this study and his sharp eyes and expert knowledge were of great value.

Lastly I would like to thank Richard Bromley for guiding my eye. over the above Danish cores and introducing me to the delights of trace fossils, particularly "paramoudra". His help in preparing the manuscript is freely acknowledged.

\section{References}

Bromley, R. G. 1979: "Chalk and Bryozoan Limestone: Facies, sediments and depositional environments". Cretaceous-Tertiary boundary symposium 1979, Vol I, 16-32, University of Copenhagen.

Håkansson, E., Bromley, R. G. and Perch-Nielsen, K., 1974: "Maastrichtian Chalk from North West Europe - A Pelagic Shelf Sediment", in HSU, K. J. and Jenkyns, H. C. (Editors) "Pelagic Sediments on Chalk and under the Sea", Special Pub.Int. Assoc. Sedimentologists. 
Hardman, R. F. P., and Eynon, G., 1977: "Valhall Field - A Structural/Stratigraphic Trap". Norwegian Petroleum Society Mesozoic Northern North Sea Symposium, Oslo 1977 MNNSS-14, 33 pp.

Hardman, R. F. P., and Kennedy, W. J., 1980: "Chalk Reservoirs of the Hod Fields, Norway". Proceeding of Symposium, "The Sedimentation of the North Sea Reservoir Rocks", Norwegian Petroleum Society, Geilo, May 1980, $31 \mathrm{pp}$.

D'Heur, M., 1980: "Chalk Reservoir of the West Ekofisk Field". Proceeding of Symposium, "The Sedimentation of the North Sea Reservoir Rocks", Geilo, May 1980, 20 pp.

Kennedy, W. J. and Garrison, R. E. 1975: "Morphology and genesis of nodular chalks and hardgrounds in the Upper Cretaceous of southern England". Sedimentology, 22, 311-386.

Kennedy, W. J., 1980: "Aspects of Chalk Sedimentation in the Southern Norwegian Offshore". Proceedings of Symposium, "The Sedimentation of the North Sea Reservoir Rocks", Norwegian Petroleum Society, Geilo, May 1980, 29 pp.
Perch-Nielsen, K., Ulleberg, K. and Evensen, J. A., 1979 Comments on "The terminal Creataceous event: a geologic problem with an oceanographic solution". Proceedings of the Cretaceous-Tertiary boundary symposium. Volume II, 16-32, University of Copenhagen.

Mapstone, N. B., 1975: Diagenetic history of a North Sea Chalk. Sedimentology (1975) 22, 601-613.

Scholle, P. A., 1974: Diagenesis of Upper Cretaceous Chalks from England, Northern Ireland and the North Sea. In K. J. HSU and H. C. Jenkyns (Eds.). Pelagic Sediments on Land and under the Sea. Spec. Publ. Int. Ass. Sediment. 1: 177-210.

Scholle, P. A., 1977: Chalk Diagenesis and its Relation to Petroleum Exploration: Oil from Chalks, a Modern Miracle? Bull. Am. Ass. Petrol. Geol. 61: 982-1009.

Watts. N. L., Lapré, J. F., van Schyndel-Goester, F. S., Ford, A., 1980: Upper Cretaceous and Lower Tertiary Chalks of the Albuskjell Area, North Sea: Deposition in a Slope and a Base-of-Slope Environment. Geology, 8, 217-221, May 1980.

Ziegler, P. A., 1977: Geology and Hydrocarbon Provinces of the North Sea. Geojournal 1 (1) 7-32. 